\title{
Ambient Air Pollution and
} Hospitalizations for Ischemic Stroke: A Time Series Analysis Using a Distributed Lag Nonlinear Model in Chongqing, China

\author{
Hao Chen ${ }^{1+}$, Zheng Cheng ${ }^{1+}$, Mengmeng $\mathrm{Li}^{1}$, Pan Luo ${ }^{1}$, Yong Duan ${ }^{1}$, Jie Fan ${ }^{1}$, Ying Xu ${ }^{1}$, \\ Kexue $\mathrm{Pu}^{2}$ and Li Zhou ${ }^{1 *}$ \\ 1 Department of Epidemiology, School of Public Health and Management, Chongqing Medical University, Chongqing, China, \\ ${ }^{2}$ College of Medical Informatics, Chongqing Medical University, Chongqing, China
}

OPEN ACCESS

Edited by:

Yuewei Liu,

Sun Yat-sen University, China

Reviewed by:

Yansen Bai,

Guangzhou Medical University, China

Tao Liu,

Guangdong Provincial Center for

Disease Control and Prevention, China

*Correspondence:

Li Zhou

zhouli_ti@163.com

tThese authors have contributed equally to this work

Specialty section:

This article was submitted to Environmental health and Exposome,

a section of the journa

Frontiers in Public Health

Received: 22 August 2021 Accepted: 02 December 2021

Published: 18 January 2022

Citation:

Chen H, Cheng Z, Li M, Luo P, Duan Y, Fan J, Xu Y, Pu K and Zhou L

(2022) Ambient Air Pollution and Hospitalizations for Ischemic Stroke: A

Time Series Analysis Using a

Distributed Lag Nonlinear Model in

Chongqing, China.

Front. Public Health 9:762597.

doi: 10.3389/fpubh.2021.762597
Short-term exposure to air pollution has been associated with ischemic stroke (IS) hospitalizations, but the evidence of its effects on IS in low- and middle-income countries is limited and inconsistent. We aimed to quantitatively estimate the association between air pollution and hospitalizations for IS in Chongqing, China. This time series study included 2,299 inpatients with IS from three hospitals in Chongqing from January 2015 to December 2016. Generalized linear regression models combined with a distributed lag nonlinear model (DLNM) were used to investigate the impact of air pollution on IS hospitalizations. Stratification analysis was further implemented by sex, age, and season. The maximum lag-specific and cumulative percentage changes of IS were 1.2\% $(95 \%$ Cl: $0.4-2.1 \%$, lag 3 day) and 3.6\% (95\% Cl: 0.5-6.7\%, lag 05 day) for each $10 \mu \mathrm{g} / \mathrm{m}^{3}$ increase in $\mathrm{PM}_{2.5} ; 1.0 \%$ (95\% Cl: 0.3-1.7\%, lag 3 day) and 2.9\% (95\% Cl: 0.6-5.2\%, lag 05 day) for each $10 \mu \mathrm{g} / \mathrm{m}^{3}$ increase in $\mathrm{PM}_{10} ; 4.8 \%$ (95\% Cl: 0.1-9.7\%, lag 4 day) for each $10 \mu \mathrm{g} / \mathrm{m}^{3}$ increase in $\mathrm{SO}_{2} ; 2.5 \%(95 \% \mathrm{Cl}: 0.3-4.7 \%$, lag 3 day) and $8.2 \%(95 \% \mathrm{Cl}$ : $0.9-16.0 \%$, lag 05 day) for each $10 \mu \mathrm{g} / \mathrm{m}^{3}$ increase in $\mathrm{NO}_{2} ; 0.7 \%$ (95\% Cl: $0.0-1.5 \%$, lag 6 day) for each $10 \mu \mathrm{g} / \mathrm{m}^{3}$ increase in $\mathrm{O}_{3}$. No effect modifications were detected for sex, age, and season. Our findings suggest that short-term exposure to $\mathrm{PM}_{2.5}, \mathrm{PM}_{10}, \mathrm{SO}_{2}$, $\mathrm{NO}_{2}$, and $\mathrm{O}_{3}$ contributes to more IS hospitalizations, which warrant the government to take effective actions in addressing air pollution issues.

Keywords: air pollution, short-term, ischemic stroke, hospitalizations, DLNM

\section{INTRODUCTION}

Stroke is a predominant public health concern in the world and the leading cause of death in China, which caused 6.2 million deaths and 132 million disability-adjusted life years globally in $2017(1,2)$. In China, ischemic stroke (IS) is the main subtype of stroke, accounting for $80 \%$ of all stroke events (3). Moreover, the incidence of IS has increased sustainedly in China in recent years (4), which has generated a huge burden on healthcare costs and the economy. Therefore, identification of modifiable risk factors for IS has substantial public health implications. 
Many factors have been confirmed to be related to IS, including smoking, lacking of physical exercise, hypertension, obesity, and atrial fibrillation (5). In addition, increasing epidemiological evidence has shown a striking relationship between air pollution exposure and IS $(6,7)$. A study conducted in nine US counties demonstrated the short-term effects of $\mathrm{PM}_{10}, \mathrm{CO}, \mathrm{SO}_{2}$, and $\mathrm{NO}_{2}$ on hospitalizations for IS (8). Another study by Tian, Y. et al. observed a significant increase in hospitalizations for IS with transient increases of $\mathrm{PM}_{2.5}, \mathrm{SO}_{2}$, $\mathrm{NO}_{2}, \mathrm{O}_{3}$, and $\mathrm{CO}$ in China (9). However, most of these studies were conducted in high-income countries, and the scientific evidence that generated in low- or middle-income countries was scarce, especially in China (10). Recently, data from the National Epidemiological Survey of Stroke in China showed that the estimated mortality-to-incidence ratio (MIR) of stroke is the highest in the southwest and the lowest along the eastern and southern coasts; the proportion of registered medical doctors per 1,000 of the population is the highest in northern and eastern China and the lowest in the southwest (4). Furthermore, the geographical regions with high correlation between IS mortality and $\mathrm{PM}_{2.5}$ gradually moved from western and northern China to the southwest during 1990-2015. Therefore, it was of great importance to explore the associations between air pollution and IS in the southwest.

Chongqing is a major heavy industrialized city located in Southwest China. Heavy industry and valley basin structure contributed to some of the worst air pollution in comparison with China's other cities. Thus, it is more meaningful to study the associations between the ambient air pollution and the occurrence of IS in Chongqing.

In this study, we conducted a time series analysis to investigate the associations between short-term exposure to air pollution and daily IS hospitalizations in Chongqing, China.

\section{MATERIALS AND METHODS}

\section{Study Area and Health Data Collection}

Chongqing is a major heavy industrialized city and one of the four municipalities in China. It is an urban city with an area of $5472.68 \mathrm{~km}^{2}$ and a population of greater than 8.6 million in 2017 (11).

Data on daily hospital admissions for IS in this study were retrieved from 3 tertiary-level comprehensive hospitals (The Second Affiliated Hospital of Chongqing Medical University, University-Town Hospital of Chongqing Medical University, and The Southeast Hospital) with approximately 3,500, 1,500, and 1,200 inpatient beds, respectively. The medical information was recorded on Platform of Medical Data Science Academy of Chongqing Medical University, and it included the patients' age, sex, diagnosis, dates of admission, and discharge. We identified admissions for IS (International Classification of Diseases (ICD)10 code I63) from January 1, 2015 to December 31, 2016 according to the 10th revision of ICD-10 codes.

\section{Environmental Data}

Data on air pollution, including levels of $\mathrm{PM}_{2.5}, \mathrm{PM}<$ $10 \mu \mathrm{m}$ in aerodynamic diameter $\left(\mathrm{PM}_{10}\right)$, sulfur dioxide $\left(\mathrm{SO}_{2}\right)$, nitrogen dioxide $\left(\mathrm{NO}_{2}\right)$, carbon monoxide $(\mathrm{CO})$, and ozone $\left(\mathrm{O}_{3}\right)$ between January 1, 2015 and December 31, 2016, were obtained from the China Air Quality Online Monitoring and Analysis Platform. There were 17 fixed monitoring stations that measure concentrations of air pollution in Chongqing. In the Chinese air quality online monitoring system, $\mathrm{PM}_{10}$ and $\mathrm{PM}_{2.5}$ were monitored by continuous automatic $\beta$-ray monitoring method, $\mathrm{SO}_{2}$ and $\mathrm{O}_{3}$ by ultraviolet fluorescence, and $\mathrm{NO}_{2}$ by chemiluminescence. These measurements were completed in adherence to the China National Quality Control (GB30952012) protocol. We derived 24 -h mean concentrations of these pollutants in Chongqing to represent each individual's daily exposure levels except for ozone (by averaging 8-h maximum values). Weather conditions including daily mean temperature and mean relative humidity were sourced from the National Meteorological Information Center of China. All the monitoring stations and hospitals were located in urban areas (Figure 1).

\section{Statistical Analysis}

Spearman's correlation coefficient was applied to explore the correlation between air pollutants and meteorological factors. For the time series analysis, we used generalized linear model combined with a distributed lag non-linear model (DLNM) to investigate both non-linear and delayed effects of air pollutants on daily hospitalizations for IS. As daily IS hospital admissions data being quantitative data, belonging to small probability events, and conforming to Poisson distribution, there a Poisson regression models allowing for overdispersion was used. The model is as follows:

$$
\begin{aligned}
\log (Y t)= & \alpha+c b(X t, \text { lag })+c b(\text { Mean Temt }, \text { lag }) \\
& +n s(R H t, d f=3)+n s(\text { Timet }, d f=7 * \text { years }) \\
& + \text { factor }(D O W)+\text { factor }(\text { holiday })
\end{aligned}
$$

where $t$ is day of observation, $Y t$ refers to the number of IS hospital admissions, $c b(X t$, lag) and $c b$ (Mean Temt, lag) indicate the matrix of air pollution and mean temperature by applying the DLNM, Xt and Mean Temt represent pollutant concentrations and mean temperature at day $\mathrm{t}, n s(R H t, d f=3)$ are natural cubic spline with 3 degrees of freedom for daily relative humidity, $n s$ (Timet, $d f=7 *$ year) is 7 degrees of freedom per year, to control long-term trend and seasonality $(12,13)$, DOW is the day of the week, and holiday is the variable for the holiday effect. We adopt a linear and a natural cubic spline $(d f=3)$ function to fit the exposure-response relationship and the lag-response relationship, respectively (13). Also, the parameter of lag-response relationship between mean temperature and IS was equal to air pollutants. Furthermore, the non-linear relationship between air pollution and IS was explored by a natural cubic spline function $(d f=3)$ when the cumulative effect appears to be strongest.

Previous studies had shown that the lagged effect of air pollutants was usually short. In this study, single-day lags (from lag 0 day to lag 7 day) combined with cumulative lags (from lag 01 day to lag 07 day) were applied to evaluate the lagged effects of air pollutants. We initially performed single-pollutant model to assess the association between air pollution and IS 


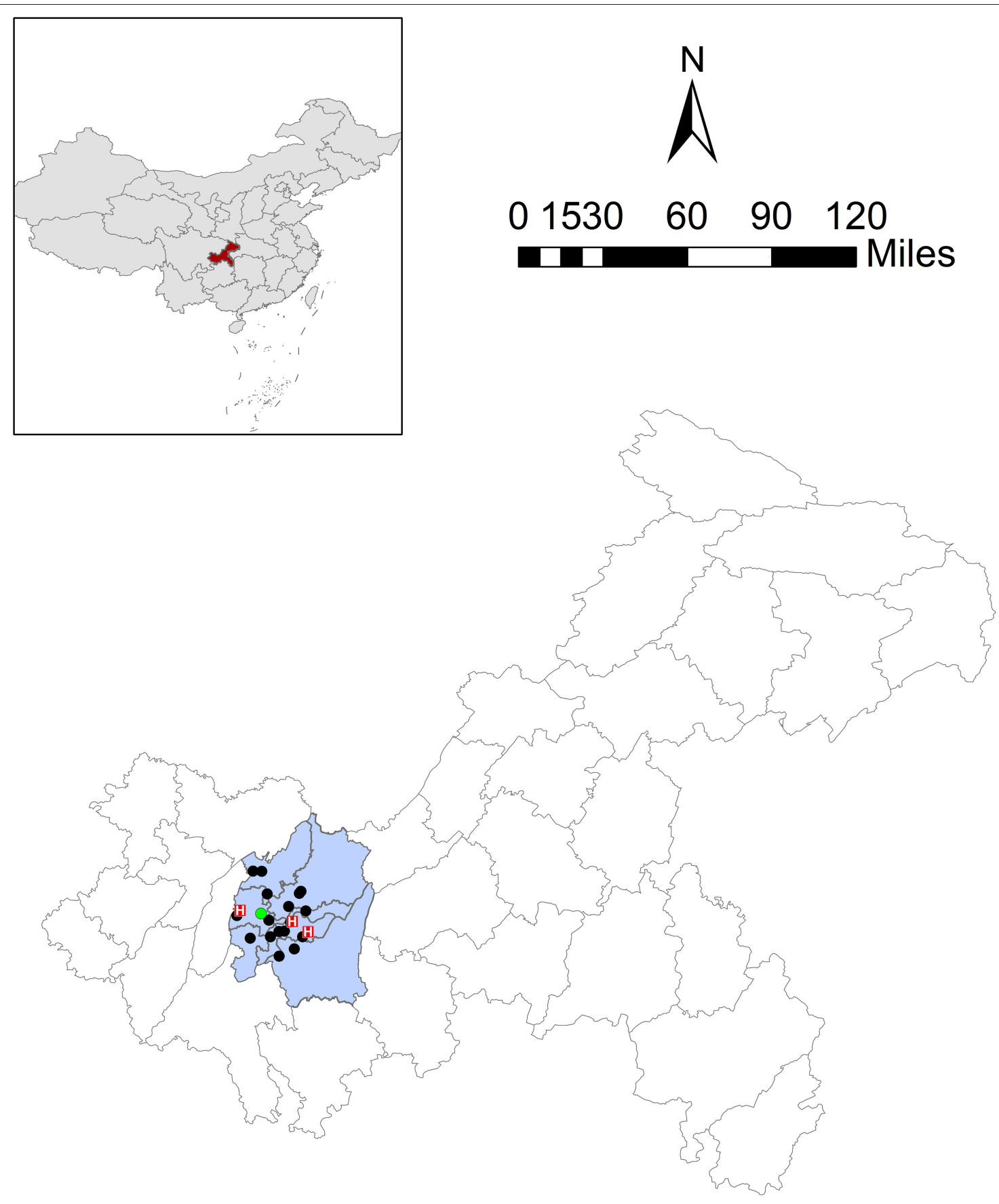

- Weather monitoring stations

(⿴囗十) Hospital

- Air monitoring stations

FIGURE 1 | Spatial distributions of air quality monitoring stations, weather monitoring stations, and addresses of hospitals in Chongqing, China. 
TABLE 1 | Distribution of daily IS admissions, air pollutants, and meteorological factors in Chongqing, China (January 2015-December 2016).

\begin{tabular}{|c|c|c|c|c|c|c|c|c|c|c|}
\hline Variables & Mean \pm SD & Min & P10 & P25 & P50 & P75 & P90 & P95 & P99 & Max \\
\hline $\begin{array}{l}\text { Cardiovascular and } \\
\text { cerebrovascular disease }\end{array}$ & $20.48 \pm 9.49$ & 2.0 & 9.0 & 13.0 & 19.0 & 26.0 & 34.0 & 38.0 & 47.0 & 57.0 \\
\hline IS & $3.15 \pm 2.00$ & 0.0 & 1.0 & 2.0 & 3.0 & 4.0 & 6.0 & 7.0 & 9.0 & 13.0 \\
\hline \multicolumn{11}{|l|}{ Gender } \\
\hline Male & $1.35 \pm 1.23$ & 0.0 & 0.0 & 0.0 & 1.0 & 2.0 & 3.0 & 4.0 & 5.0 & 7.0 \\
\hline Female & $1.80 \pm 1.45$ & 0.0 & 0.0 & 1.0 & 2.0 & 3.0 & 4.0 & 5.0 & 6.0 & 7.0 \\
\hline \multicolumn{11}{|l|}{ Age } \\
\hline$<75$ & $1.07 \pm 1.08$ & 0.0 & 0.0 & 0.0 & 1.0 & 2.0 & 3.0 & 3.0 & 4.0 & 6.0 \\
\hline$\geq 75$ & $2.07 \pm 1.55$ & 0.0 & 0.0 & 1.0 & 2.0 & 3.0 & 4.0 & 5.0 & 6.0 & 10.0 \\
\hline \multicolumn{11}{|l|}{ Season } \\
\hline Warm & $3.06 \pm 1.95$ & 0.0 & 1.0 & 2.0 & 3.0 & 4.0 & 6.0 & 7.0 & 8.0 & 13.0 \\
\hline Cold & $3.23 \pm 2.04$ & 0.0 & 1.0 & 2.0 & 3.0 & 5.0 & 6.0 & 7.0 & 9.0 & 10.0 \\
\hline $\mathrm{PM}_{2.5}\left(\mu \mathrm{g} / \mathrm{m}^{3}\right)$ & $54.41 \pm 30.72$ & 10.0 & 25.0 & 34.0 & 46.0 & 66.0 & 93.0 & 114.0 & 164.1 & 212.0 \\
\hline $\mathrm{PM}_{10}\left(\mu \mathrm{g} / \mathrm{m}^{3}\right)$ & $81.75 \pm 40.68$ & 13.0 & 41.0 & 54.0 & 74.0 & 98.0 & 131.0 & 164.5 & 228.8 & 293.0 \\
\hline $\mathrm{SO}_{2}\left(\mu \mathrm{g} / \mathrm{m}^{3}\right)$ & $14.55 \pm 6.59$ & 4.0 & 7.0 & 10.0 & 13.0 & 18.0 & 23.0 & 27.0 & 36.4 & 42.0 \\
\hline $\mathrm{CO}\left(\mathrm{mg} / \mathrm{m}^{3}\right)$ & $1.04 \pm 0.28$ & 0.4 & 0.7 & 0.9 & 1.0 & 1.2 & 1.4 & 1.5 & 1.8 & 3.4 \\
\hline $\mathrm{NO}_{2}\left(\mu \mathrm{g} / \mathrm{m}^{3}\right)$ & $45.05 \pm 12.69$ & 16.0 & 30.0 & 36.0 & 44.0 & 53.0 & 62.0 & 69.0 & 79.0 & 96.0 \\
\hline $\mathrm{O}_{3}\left(\mu \mathrm{g} / \mathrm{m}^{3}\right)$ & $68.11 \pm 45.38$ & 4.0 & 15.0 & 29.0 & 60.0 & 101.0 & 135.0 & 150.5 & 184.3 & 223.0 \\
\hline Temperature $\left({ }^{\circ} \mathrm{C}\right)$ & $19.60 \pm 7.47$ & 1.2 & 9.6 & 13.0 & 20.1 & 25.2 & 29.4 & 31.4 & 34.3 & 36.2 \\
\hline Relative humidity (\%) & $75.36 \pm 10.93$ & 43.0 & 60.3 & 68.0 & 76.0 & 84.0 & 90.0 & 92.0 & 94.6 & 96.3 \\
\hline
\end{tabular}

$\mathrm{PM}_{2.5}$, particles with aerodynamic diameter < $2.5 \mu \mathrm{m} ; \mathrm{PM}_{10}$, particles with aerodynamic diameter $<10 \mu \mathrm{m}$; $\mathrm{SO}_{2}$, sulfur dioxide; $\mathrm{NO}_{2}$, nitrogen dioxide; $\mathrm{CO}$, carbon monoxide; $\mathrm{O}_{3}$, ozone; IS, ischemic stroke.

hospitalizations, and then, the significant air pollutants were included in subsequent analysis.

We conducted stratification analysis to explore the potential effect modification by age ( $<75, \geq 75$ years), sex (male, female), and season [cold season, warm season). The risk estimates were expressed in terms of the percentage changes (excess risk, ER (\%)] in IS hospitalizations per $10 \mu \mathrm{g} / \mathrm{m}^{3}$ increment of air pollutants (except that CO was per $1 \mathrm{mg} / \mathrm{m}^{3}$ ) and their respective $95 \%$ confidence intervals (CIs). We further evaluated the statistical significance of the differences as $(Q 1-Q 2) / \sqrt{ } S E 1^{2}+S E 2^{2}$, such that the $Q 1$ and $\hat{Q} 2$ represent the estimates for the two subgroups, and SE1 and SE2 represent their respective standard errors.

Sensitivity analysis was also performed to identify the robustness of the results by (a) fitting two-pollutant models. Correlation coefficient $r>0.60$ between air pollutants was not included in multipollutant model to avoid collinearity; (b) changing the degrees of freedom in the natural cubic spline function of time (6-8 df) and meteorological variables (4-6 $d f)$. All analyses were conducted through "dlnm" and "splines" packages in $\mathrm{R}$ software (version 3.6.3). p-Value less than 0.05 was considered as statistically significant.

\section{RESULTS}

Basic characteristics of patients with IS, meteorological factors, and air pollution are displayed in Table 1. There was a total of 14,969 hospital admissions for cardiovascular and cerebrovascular diseases from 3 hospitals during January 1, 2015 to December 31, 2016. Overall, 2,299 patients with IS formed the basis of this study, with a daily average of 3 cases. $57.1 \%$ were men and $65.9 \%$ were patients aged $\geq 75$ years. The mean $24-\mathrm{h} \mathrm{PM}_{2.5}$, $\mathrm{PM}_{10}, \mathrm{SO}_{2}, \mathrm{CO}, \mathrm{NO}_{2}$, and 8-h maximum $\mathrm{O}_{3}$ concentrations were $54.41 \mu \mathrm{g} / \mathrm{m}^{3}, 81.75 \mu \mathrm{g} / \mathrm{m}^{3}, 14.55 \mu \mathrm{g} / \mathrm{m}^{3}, 1.04 \mathrm{mg} / \mathrm{m}^{3}, 45.05$ $\mu \mathrm{g} / \mathrm{m}^{3}$, and $68.11 \mu \mathrm{g} / \mathrm{m}^{3}$, respectively.

The Spearman's correlation coefficients between air pollutants and meteorological factors are listed in Table 2. $\mathrm{PM}_{2.5}, \mathrm{PM}_{10}$, $\mathrm{SO}_{2}, \mathrm{NO}_{2}$, and $\mathrm{CO}$ were positively and moderately or strongly correlated. $\mathrm{O}_{3}$ exposure was negatively and weakly associated with $\mathrm{PM}_{2.5}, \mathrm{SO}_{2}$, and $\mathrm{CO}$, whereas the correlation coefficient with $\mathrm{PM}_{10}$ and $\mathrm{NO}_{2}$ was not statistically significant. Temperature was positively associated with $\mathrm{O}_{3}$, and negatively associated with other air pollutants, whereas relative humidity was positively associated with $\mathrm{CO}$, and negatively associated with other air pollutants.

Figure 2 shows that exposure to $\mathrm{PM}_{2.5}, \mathrm{PM}_{10}, \mathrm{SO}_{2}, \mathrm{NO}_{2}$, and $\mathrm{O}_{3}$ was significantly associated with IS. In single-day lag structures, exposures to $\mathrm{PM}_{2.5}$ (lag 2 day-lag 4 day), $\mathrm{PM}_{10}$ (lag 2 day-lag 5 day), $\mathrm{SO}_{2}$ (lag 4 day), $\mathrm{NO}_{2}$ (lag 2 day, lag 3 day), and $\mathrm{O}_{3}$ (lag 6 day) were associated with increased IS cases. The maximum lag-specific percentage changes for each $10 \mu \mathrm{g} / \mathrm{m}^{3}$ increase in $\mathrm{PM}_{2.5}, \mathrm{PM}_{10}, \mathrm{SO}_{2}, \mathrm{NO}_{2}$, and $\mathrm{O}_{3}$ were $1.2 \%$ (95\% CI: 0.4-2.1\%, lag 3 day), 1.0\% (95\% CI: $0.3-1.7 \%$, lag 3 day), 4.8\% (95\% CI: $0.1-9.7 \%$, lag 4 day), 2.5\% (95\% CI: $0.3-4,7 \%$, lag 3 day), and $0.7 \%$ (95\% CI: $0.0-1.5 \%$, lag 6 day), respectively. In cumulative lag structures, the unfavorable effects of $\mathrm{PM}_{2.5}, \mathrm{PM}_{10}$, and $\mathrm{NO}_{2}$ occurred to lag 04 day-lag 06 day, lag 04 day-lag 06 day, and lag 04 day-lag 05 day, and the corresponding maximum percentage 
TABLE 2 | Spearman's correlation coefficients between air pollutants and meteorological factors.

\begin{tabular}{|c|c|c|c|c|c|c|c|c|}
\hline Variables & $\mathrm{PM}_{2.5}$ & $\mathrm{PM}_{10}$ & $\mathrm{SO}_{2}$ & Co & $\mathrm{NO}_{2}$ & $\mathrm{O}_{3}$ & Temperature & Relative humidity \\
\hline $\mathrm{PM}_{2.5}$ & 1.00 & & & & & & & \\
\hline $\mathrm{PM}_{10}$ & $0.95^{\star \star}$ & 1.00 & & & & & & \\
\hline $\mathrm{SO}_{2}$ & $0.61^{\star \star}$ & $0.68^{\star \star}$ & 1.00 & & & & & \\
\hline $\mathrm{CO}$ & $0.60^{\star \star}$ & $0.56^{\star \star}$ & $0.56^{\star \star}$ & 1.00 & & & & \\
\hline $\mathrm{NO}_{2}$ & $0.71^{\star *}$ & $0.74^{\star \star}$ & $0.61^{\star *}$ & $0.53^{\star \star}$ & 1.00 & & & \\
\hline Relative humidity & $-0.12^{\star \star}$ & $-0.29^{\star \star}$ & $-0.39^{\star \star}$ & $0.23^{\star \star}$ & $-0.14^{\star \star}$ & $-0.65^{\star \star}$ & $-0.38^{\star \star}$ & 1.00 \\
\hline
\end{tabular}

$P M_{2.5}$, particles with aerodynamic diameter < 2.5 $\mu \mathrm{m} ; \mathrm{PM}_{10}$, particles with aerodynamic diameter $<10 \mu \mathrm{m}$; $\mathrm{SO}_{2}$, sulfur dioxide; $\mathrm{NO}_{2}$, nitrogen dioxide; $\mathrm{CO}$, carbon monoxide; $\mathrm{O}_{3}$, ozone; * $p<0.05 ;{ }^{\star \star} p<0.01$.

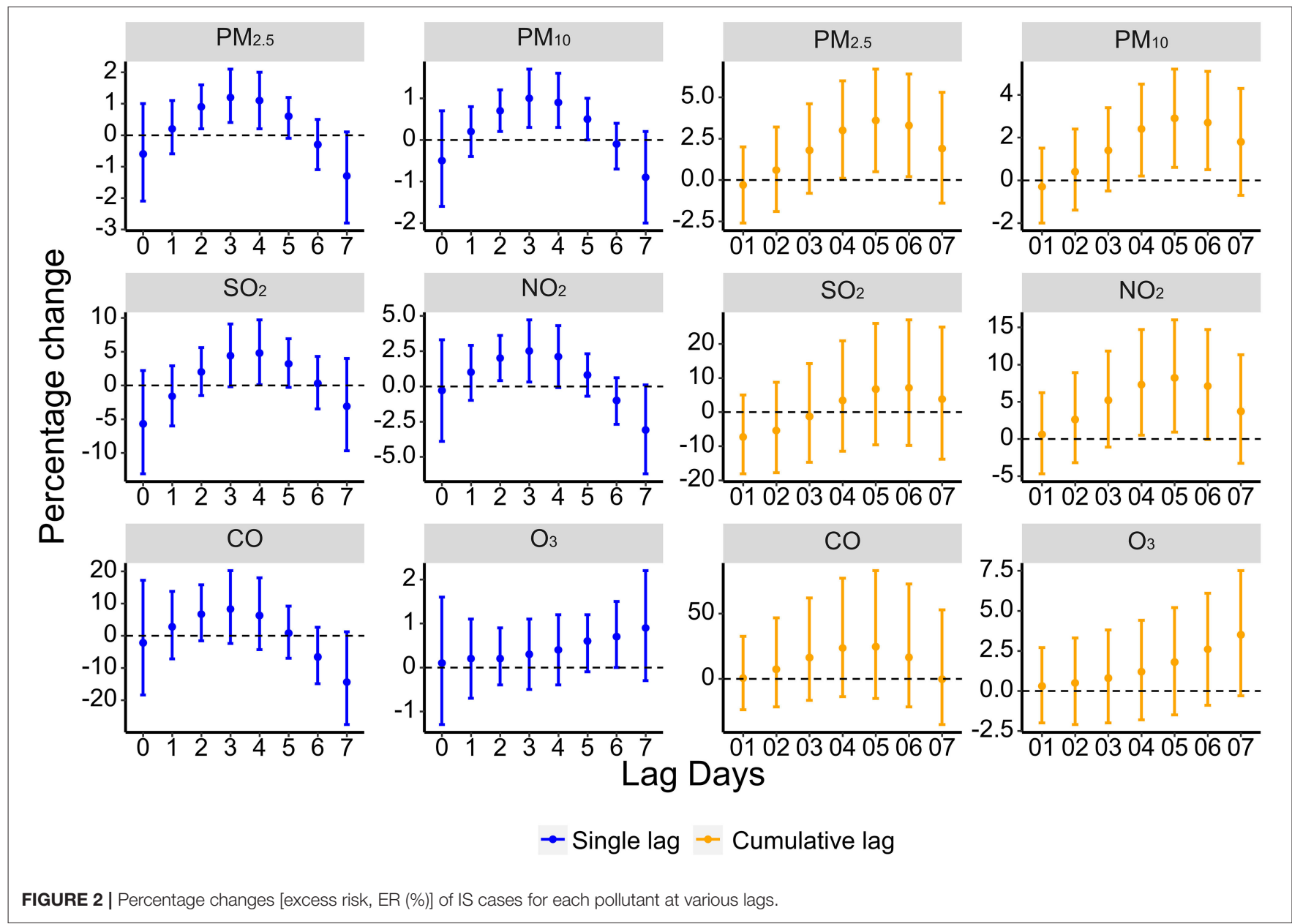

changes were $3.6 \%$ (95\% CI: $0.5-6.7 \%$, lag 05 day), $2.9 \%(95 \%$ CI: $0.6-5.2 \%$, lag 05 day), $8.2 \%$ (95\% CI: $0.9-16.0 \%$, lag 05 day) (Supplementary Table S1), whereas no association between CO and IS had been detected.

The exposure-response curves for $\mathrm{PM}_{2.5}, \mathrm{PM}_{10}, \mathrm{SO}_{2}, \mathrm{NO}_{2}$, $\mathrm{CO}$, and $\mathrm{O}_{3}$ with hospitalizations for IS are displayed in Figure 3. The exposure-response curve for $\mathrm{NO}_{2}, \mathrm{SO}_{2}$, and $\mathrm{O}_{3}$ showed thresholds for their associations with hospitalizations for IS: 50$75 \mu \mathrm{g} / \mathrm{m}^{3}$ for $\mathrm{NO}_{2}, 20-30 \mu \mathrm{g} / \mathrm{m}^{3}$ for $\mathrm{SO}_{2}$, and $100-150 \mu \mathrm{g} / \mathrm{m}^{3}$ for $\mathrm{O}_{3}$. The exposure-response relationship for $\mathrm{PM}_{2.5}, \mathrm{PM}_{10}$, and $\mathrm{CO}$ was almost linear.

Stratified and sensitivity analyses were performed on the basis of reaching the maximum effect of $\mathrm{PM}_{2.5}, \mathrm{PM}_{10}, \mathrm{SO}_{2}$, $\mathrm{NO}_{2}$, and $\mathrm{O}_{3}$ in the cumulative lag structure. The associations 

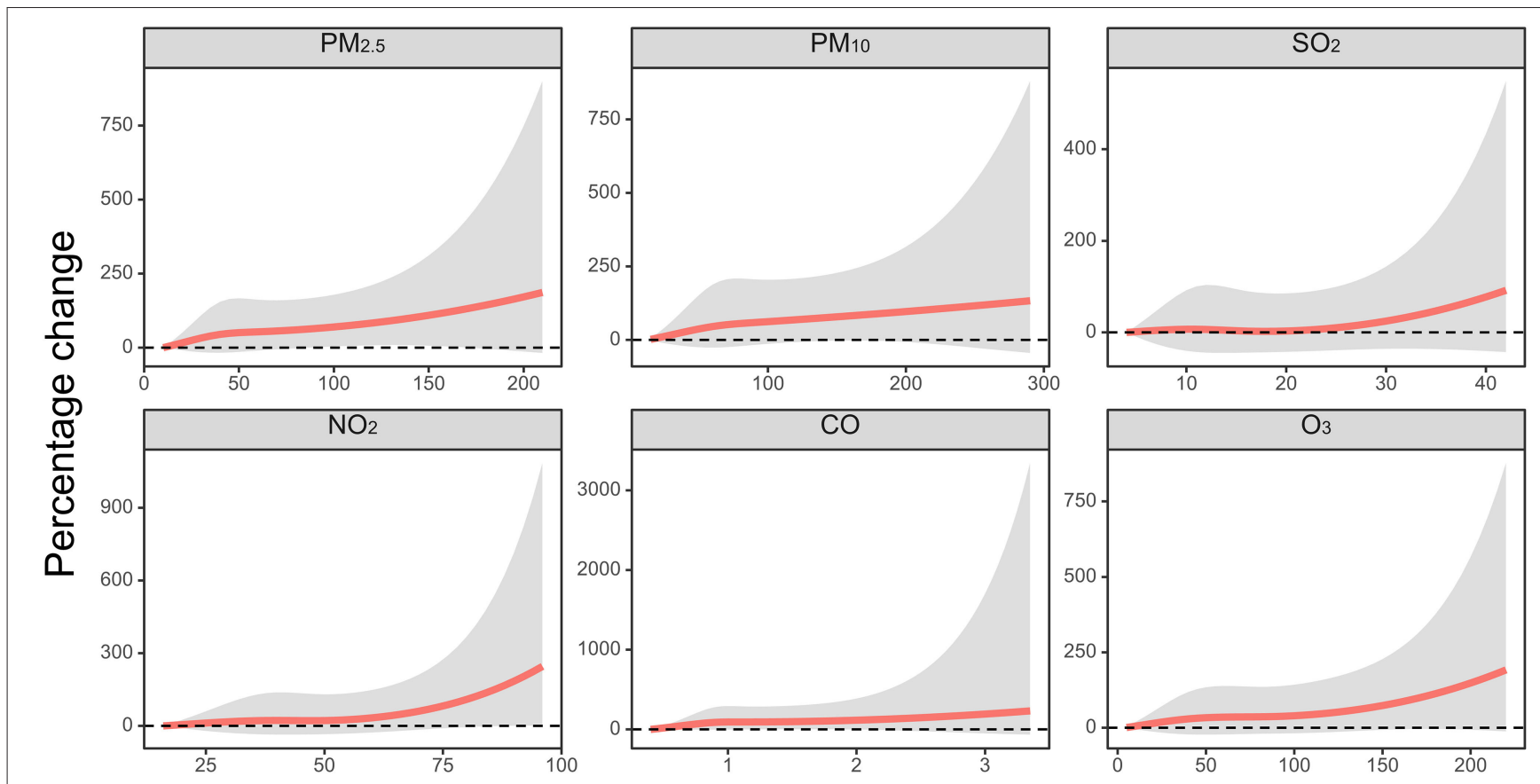

Air pollution concentration

FIGURE 3 | The concentration-response relationship curves between $\mathrm{PM}_{2.5}$ (lag 05 day), $\mathrm{PM}_{10}$ (lag 05 day), $\mathrm{SO}_{2}$ (lag 06 day), $\mathrm{NO}_{2}$ (lag 05 day), and $\mathrm{O}_{3}$ (lag 07 day) and IS hospitalizations. $X$-axis: each air pollution concentrations; $y$-axis: the percentage changes [excess risk, ER (\%)] of air pollution on IS.

TABLE 3 | Percentage changes [excess risk, ER (\%)] for IS hospitalizations with per $10 \mu \mathrm{g} / \mathrm{m}^{3}$ increase of exposure to $\mathrm{PM}_{2.5}, \mathrm{PM}_{10}, \mathrm{SO}_{2}, \mathrm{NO}_{2}$, and $\mathrm{O}_{3}$ stratified by age, sex, and season.

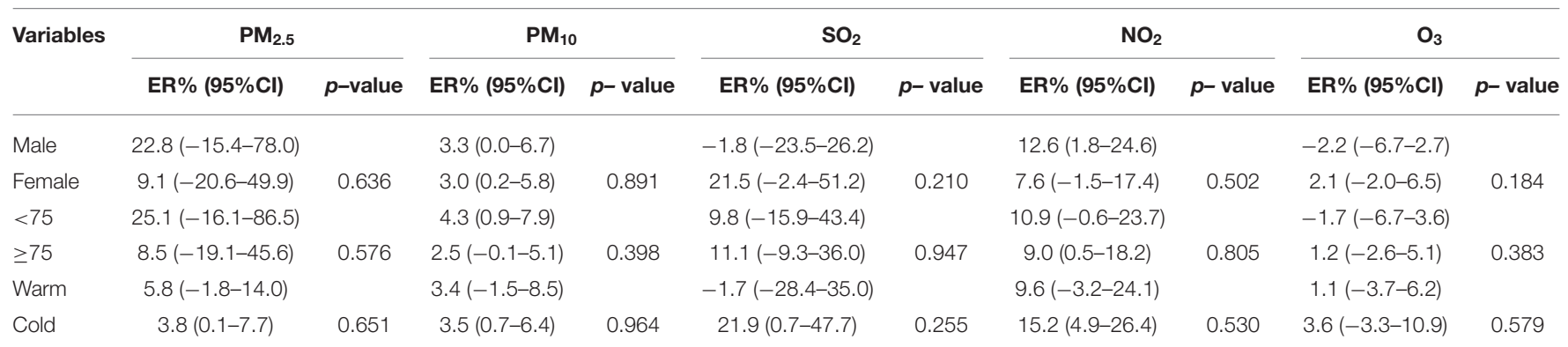

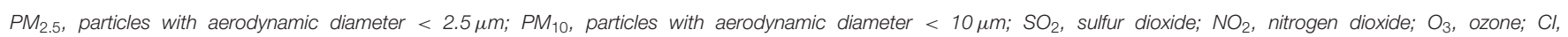
confidence intervals.

between air pollutant exposures and the hospitalizations for IS were evaluated in subgroups based on sex, age, and season (Table 3). For $\mathrm{PM}_{2.5}, \mathrm{PM}_{10}, \mathrm{SO}_{2}$, and $\mathrm{NO}_{2}$, the effects were still significant in cold season subgroup. In addition, both sex and the younger received adverse effects when exposed to $\mathrm{PM}_{10}$, whereas $\mathrm{NO}_{2}$ seems to be more susceptible to men and the elder. Although the percentage changes were somewhat different and some of them were insignificant, we did not find any significant effect modification across sex, age, and season (all $p$ for effect modification $>0.05$ ).

Table 4 provides the results of the two-pollutant model, and further adjustment for other pollutant exposures did not materially change the associations between $\mathrm{PM}_{2.5}, \mathrm{PM}_{10}, \mathrm{SO}_{2}$,
$\mathrm{NO}_{2}$, andO $\mathrm{O}_{3}$ exposures and IS. Results of the sensitivity analysis (Supplementary Table S2) indicated that the effect estimates of the association between air pollution and IS hospitalizations were not substantially affected with the use of alternative $d f$ value for time (6-8 per year), temperature (3-6), and relative humidity (3$6)$, although some of the associations became insignificant for temperature $(d f=6)$.

\section{DISCUSSION}

There is growing interest in the associations between ambient air pollution and risk of IS, but data on the associations in low- 
TABLE 4 | Percentage changes [excess risk, ER (\%)] of IS for each pollutant in two-pollutant model.

\begin{tabular}{|c|c|c|c|}
\hline & & ER\% $(95 \% \mathrm{Cl})$ & $p$-value \\
\hline \multirow[t]{2}{*}{$\mathrm{PM}_{2.5}$} & NULL & $3.6(0.5-6.7)$ & \\
\hline & $\mathrm{O}_{3}$ & $2.7(-0.5-6.1)$ & 0.715 \\
\hline \multirow[t]{3}{*}{$\mathrm{PM}_{10}$} & NULL & $2.9(0.6-5.2)$ & \\
\hline & $\mathrm{CO}$ & $2.7(0.0-5.4)$ & 0.907 \\
\hline & $\mathrm{O}_{3}$ & $2.3(-0.2-4.8)$ & 0.759 \\
\hline \multirow[t]{3}{*}{$\mathrm{SO}_{2}$} & NULL & $7.1(-9.8-27.0)$ & \\
\hline & $\mathrm{CO}$ & $3.4(-13.5-23.7)$ & 0.787 \\
\hline & $\mathrm{O}_{3}$ & $0.6(-16.2-20.7)$ & 0.626 \\
\hline \multirow[t]{3}{*}{$\mathrm{NO}_{2}$} & NULL & $8.2(0.9-16.0)$ & \\
\hline & $\mathrm{CO}$ & $7.0(-1.2-15.8)$ & 0.838 \\
\hline & $\mathrm{O}_{3}$ & $6.8(-1.0-15.1)$ & 0.789 \\
\hline \multirow[t]{6}{*}{$\mathrm{O}_{3}$} & NULL & $3.5(-0.3-7.5)$ & \\
\hline & $\mathrm{PM}_{2.5}$ & $2.6(-1.4-6.9)$ & 0.778 \\
\hline & $\mathrm{PM}_{10}$ & $2.2(-2.0-6.6)$ & 0.672 \\
\hline & $\mathrm{SO}_{2}$ & $3.4(-0.6-7.6)$ & 0.971 \\
\hline & $\mathrm{NO}_{2}$ & $3.0(-1.1-7.3)$ & 0.888 \\
\hline & $\mathrm{CO}$ & $3.3(-0.5-7.3)$ & 0.970 \\
\hline
\end{tabular}

$P M_{2.5}$, particles with aerodynamic diameter $<2.5 \mu \mathrm{m} ; P_{10}$, particles with Aerodynamic diameter < $10 \mu \mathrm{m} ; \mathrm{SO}_{2}$, sulfur dioxide; $\mathrm{NO}_{2}$, nitrogen dioxide; $\mathrm{O}_{3}$, ozone; $\mathrm{Cl}$, confidence intervals.

or middle-income cities are still limited, especially in Southwest China. Chongqing is mainly associated with heavy industry with a valley basin structure, which has a great impact on ambient air pollution. Therefore, we conducted this time series study combining with DLNM to evaluate the short-term effects of ambient air pollutants on hospitalizations for IS in Chongqing. The data obtained in this analysis indicated that short-term exposure to $\mathrm{PM}_{2.5}, \mathrm{PM}_{10}, \mathrm{NO}_{2}, \mathrm{O}_{3}$, and $\mathrm{SO}_{2}$ was significantly associated with increased hospitalizations for IS. Age, sex, and season did not appear to significantly modify the associations between short-term exposure to air pollution and IS onset. The sensitivity analysis showed a robustness of the pollutant model results.

In single-pollutant models, we found that each $10 \mu \mathrm{g} / \mathrm{m}^{3}$ increase in $\mathrm{PM}_{2.5}, \mathrm{PM}_{10}, \mathrm{SO}_{2}, \mathrm{NO}_{2}$, and $\mathrm{O}_{3}$ was associated with a $1.2,1.0,4.8,2.5$, and $0.7 \%$ increase in IS hospitalizations, respectively, which were similar to several previous studies (14-16). For example, Hu's study conducted in Yancheng city has shown that IS hospitalizations increased 1.06\% (95\% CI: $0.21-1.91 \%$ ) per $10 \mu \mathrm{g} / \mathrm{m}^{3}$ increase in $\mathrm{PM}_{2.5}$ (14). Another multicity study reported that per $10 \mu \mathrm{g} / \mathrm{m}^{3}$ evaluation of $\mathrm{NO}_{2}$ was associated with $2.6 \%$ change in hospitalizations for IS (15). Wellenius et al. investigated the association of air pollution with hospitalizations for IS in nine US cities, with a cohort restricted to patients aged above 65 years. They observed that an elevation of IQR in $\mathrm{PM}_{10}\left(22.96 \mu \mathrm{g} / \mathrm{m}^{3}\right), \mathrm{SO}_{2}\left(6.69 \mu \mathrm{g} / \mathrm{m}^{3}\right)$, and $\mathrm{NO}_{2}(11.93$ $\left.\mu \mathrm{g} / \mathrm{m}^{3}\right)$ concentrations was associated with $1.03,1.35$, and $2.94 \%$ increases in hospitalizations for IS, respectively (8). Another study conducted in Guangzhou indicated that each IQR increase of $\mathrm{PM}_{2.5}\left(41 \mu \mathrm{g} / \mathrm{m}^{3}\right), \mathrm{O}_{3}\left(99 \mu \mathrm{g} / \mathrm{m}^{3}\right), \mathrm{SO}_{2}\left(15 \mu \mathrm{g} / \mathrm{m}^{3}\right)$, and
$\mathrm{NO}_{2}\left(44 \mu \mathrm{g} / \mathrm{m}^{3}\right)$ corresponded to an $\mathrm{RR}$ value of $1.0272,1.0173$, $1.0344,1.0423$, respectively (17). In addition, a nationwide time series analysis in China indicated that each increase of $10 \mu \mathrm{g} / \mathrm{m}^{3}$ in $\mathrm{PM}_{2.5}, \mathrm{SO}_{2}$, and $\mathrm{NO}_{2}$ was associated with a $0.34,1.37$, and $1.82 \%$ increase in hospitalizations for IS (9). Their studies suggest that the major components of air pollutants vary significantly from region to region, which does affect the occurrence of IS in different cities.

In China, the evidence of the effect of $\mathrm{CO}$ exposure on IS risk is still controversial. A study conducted in Taiwan found that CO was significantly and positively associated with IS hospitalizations in the single-pollutant model, but it became insignificant in the multipollutant model (18). However, research from Hong Kong observed a negative association between ambient CO concentrations and stroke hospitalizations (19). In addition, several other studies in China found no association between CO and IS risk $(15,20)$, which was consistent with our results. The inconsistency of the results on the associations between $\mathrm{CO}$ and IS might be attributable to variations in air pollution levels, outcome definitions, weather conditions, population susceptibility, and sociodemographic characteristics across studies.

The identification of potentially susceptible subpopulations has significant implications for public health. Some studies did not identify any effect modification by sex and age between air pollution and IS (21-23), which were in line with our study. In addition, this study found no effect modification by season, whereas the adverse effects of $\mathrm{PM}_{2.5}, \mathrm{PM}_{10}, \mathrm{NO}_{2}$, and $\mathrm{SO}_{2}$ remained significant in cold season. This may be attributable to a high number of foggy days during cold season in Chongqing. During our study period, the mean AQI in Chongqing (80.75) was higher than a less foggy city, such as Guangzhou (68.79), which was similar to Chongqing in population and land area (24).

The biological mechanism of air pollution-induced IS has not been fully investigated. Several possible mechanisms have been proposed to be related to the inflammation (25), oxidative stress (26), abnormal lipid metabolism (7, 27), and autonomic dysfunction (7). For example, $\mathrm{PM}_{2.5}$ can trigger the release of pro-inflammatory mediators causing systemic inflammation, which impaired blood-brain barrier (BBB) stability and induces to the generation of ROS and oxidative stress (28). Inhalation of $\mathrm{SO}_{2}$ can affect heart rate variability, increase oxidation, and exacerbate blood clotting and thrombosis formation (29). In addition, a study showed that exposure to $\mathrm{O}_{3}$ and particulate pollutants increased endothelin 1, leading to vascular endothelial dysfunction and subsequent brain damage (30).

Our study has some potential limitations. First, small sample sizes might lead to lower statistical power; therefore, subsequent studies with large sample sizes would be expected. Second, city-level concentration of air pollution rather than individual exposure was utilized as the exposure concentration, which might underestimate the effect of air pollution. Third, we selected only 3 hospitals in one single city, so the generalization of the results requires caution. Finally, although we adjusted for several confounders such as seasonality, day of week, public 
holiday, and weather conditions, there might exist some other confounding factors.

\section{CONCLUSIONS}

This study suggests that short-term exposure to $\mathrm{PM}_{2.5}, \mathrm{PM}_{10}$, $\mathrm{NO}_{2}, \mathrm{O}_{3}$, and $\mathrm{SO}_{2}$ was associated with increased hospitalizations for IS in Chongqing, China. Our study provides new evidence on the association between air pollution and IS. Further studies are warranted to help government effectively reduce the burden of air pollution.

\section{DATA AVAILABILITY STATEMENT}

The raw data supporting the conclusions of this article will be made available by the authors, without undue reservation.

\section{ETHICS STATEMENT}

The studies involving human participants were reviewed and approved by Ethics Committee of Chongqing Medical University in Chongqing, China. Written informed consent to participate in this study was provided by the participants' legal guardian/next of kin.

\section{REFERENCES}

1. Roth GA, Abate D, Abate KH, Abay SM, Abbafati C, Abbasi N, et al. Global, regional, and national age-sex-specific mortality for 282 causes of death in 195 countries and territories, 1980-2017: a systematic analysis for the Global Burden of Disease Study 2017. Lancet. (2018) 392:1736-88. doi: 10.1016/s0140-6736(18)32203-7

2. Johnson CO, Nguyen M, Roth GA, Nichols E, Alam T, Abate D, et al. Global, regional, and national burden of stroke, 1990-2016: a systematic analysis for the Global Burden of Disease Study 2016. Lancet Neurol. (2019) 18:439-58. doi: 10.1016/s1474-4422(19)30034-1

3. Liu L, Wang D, Wong KS, Wang Y. Stroke and stroke care in China: huge burden, significant workload, and a national priority. Stroke. (2011) 42:3651-4. doi: 10.1161/STROKEAHA.111.635755

4. Wu S, Wu B, Liu M, Chen Z, Wang W, Anderson CS, et al. Stroke in China: advances and challenges in epidemiology, prevention, and management. Lancet Neurol. (2019) 18:394-405. doi: 10.1016/S1474-4422(18)30500-3

5. Li N, Wang X, Sun C, Wu X, Lu M, Si Y, et al. Change of intestinal microbiota in cerebral ischemic stroke patients. BMC Microbiol. (2019) 19:191. doi: 10.1186/s12866-019-1552-1

6. Guo Y, Xie X, Lei L, Zhou H, Deng S, Xu Y, et al. Short-term associations between ambient air pollution and stroke hospitalisations: time-series study in Shenzhen, China. BMJ Open. (2020) 10:e032974. doi: 10.1136/bmjopen-2019-032974

7. Chung JW, Bang OY, Ahn K, Park SS, Park TH, Kim JG, et al. Air pollution is associated with ischemic stroke via cardiogenic embolism. Stroke. (2017) 48:17-23. doi: 10.1161/STROKEAHA.116.015428

8. Wellenius GA, Schwartz J, Mittleman MA. Air pollution and hospital admissions for ischemic and hemorrhagic stroke among medicare beneficiaries. Stroke. (2005) 36:2549-53. doi: 10.1161/01.STR.0000189687.78760.47

9. Tian Y, Liu H, Zhao Z, Xiang X, Li M, Juan J, et al. Association between ambient air pollution and daily hospital admissions for ischemic stroke: a nationwide time-series analysis. PLoS Med. (2018) 15:e1002668. doi: 10.1371/journal.pmed.1002668

\section{AUTHOR CONTRIBUTIONS}

HC wrote the manuscript and analyzed the data. PL and YD collected and inputted the data. JF, YX, ML, ZC, KP, and LZ reviewed the results and provided guidelines for presentation and interpretation. All authors have read and approved the final manuscript.

\section{FUNDING}

This study was funded by Intelligent Medicine Research Project of Chongqing Medical University (Number: ZHYX202026) and Intelligent Medicine Research Project for Graduate Students of Chongqing Medical University (Number: YJSZHYX202018).

\section{ACKNOWLEDGMENTS}

We thank the Medical Data Science Academy of Chongqing Medical University for providing population health data.

\section{SUPPLEMENTARY MATERIAL}

The Supplementary Material for this article can be found online at: https://www.frontiersin.org/articles/10.3389/fpubh. 2021.762597/full\#supplementary-material

10. Shah AS, Lee KK, McAllister DA, Hunter A, Nair H, Whiteley W, et al. Short term exposure to air pollution and stroke: systematic review and meta-analysis. BMJ. (2015) 350:h1295. doi: 10.1136/bmj.h1295

11. Tang C, Chen Y, Song Q, Ma J, Zhou Y, Gong L, et al. Shortterm exposure to air pollution and occurrence of emergency stroke in Chongqing, China. Int Arch Occup Environ Health. (2021) 94:69-76. doi: 10.1007/s00420-020-01557-y

12. Zhang Y, Ni H, Bai L, Cheng Q, Zhang H, Wang S, et al. The short-term association between air pollution and childhood asthma hospital admissions in urban areas of Hefei City in China: a time-series study. Environ Res. (2019) 169:510-6. doi: 10.1016/j.envres.2018.11.043

13. Huang K, Ding K, Yang XJ, Hu CY, Jiang W, Hua XG, et al. Association between short-term exposure to ambient air pollutants and the risk of tuberculosis outpatient visits: a time-series study in Hefei, China. Environ Res. (2020) 184:109343. doi: 10.1016/j.envres.2020.109343

14. Hu W, Chen Y, Chen J. Short-term effect of fine particular matter on daily hospitalizations for ischemic stroke: a time-series study in Yancheng, China. Ecotoxicol Environ Saf. (2021) 208:111518. doi: 10.1016/j.ecoenv.2020.111518

15. Liu H, Tian Y, Xu Y, Huang Z, Huang C, Hu Y, et al. Association between ambient air pollution and hospitalization for ischemic and hemorrhagic stroke in China: a multicity case-crossover study. Environ Pollut. (2017) 230:234-41. doi: 10.1016/j.envpol.2017.06.057

16. Wang Y, Eliot MN, Wellenius GA. Short-term changes in ambient particulate matter and risk of stroke: a systematic review and meta-analysis. J Am Heart Assoc. (2014) 3:e000983. doi: 10.1161/JAHA.114.000983

17. Guo P, Wang Y, Feng W, Wu J, Fu C, Deng H, et al. Ambient air pollution and risk for ischemic stroke: a short-term exposure assessment in South China. Int J Environ Res Public Health. (2017) 14:1091. doi: 10.3390/ijerph140 91091

18. Tsai SS, Goggins WB, Chiu HF, Yang CY. Evidence for an association between air pollution and daily stroke admissions in Kaohsiung, Taiwan. Stroke. (2003) 34:2612-6. doi: 10.1161/01.STR.0000095564.33543.64

19. Tian L, Qiu H, Pun VC, Ho KF, Chan CS Yu IT. Carbon monoxide and stroke: A time series study of ambient air pollution and emergency hospitalizations. Int J Cardiol. (2015) 201:4-9. doi: 10.1016/j.ijcard.2015.07.099 
20. Wang Z, Peng J, Liu P, Duan Y, Huang S, Wen Y, et al. Association between short-term exposure to air pollution and ischemic stroke onset: a time-stratified case-crossover analysis using a distributed lag nonlinear model in Shenzhen, China. Environ Health. (2020) 19:1. doi: 10.1186/s12940-019-0557-4

21. Villeneuve PJ, Chen L, Stieb D, Rowe BH. Associations between outdoor air pollution and emergency department visits for stroke in Edmonton, Canada. Eur J Epidemiol. (2006) 21:689-700. doi: 10.1007/s10654-006-9050-9

22. Huang F, Luo Y, Guo Y, Tao L, Xu Q, Wang C, et al. Particulate matter and hospital admissions for stroke in Beijing, China: modification effects by ambient temperature. J Am Heart Assoc. (2016) 5:e003437. doi: 10.1161/JAHA.116.003437

23. Tian Y, Xiang X, Wu Y, Cao Y, Song J, Sun K, et al. Fine particulate air pollution and first hospital admissions for ischemic stroke in Beijing, China. Sci Rep. (2017) 7:3897. doi: 10.1038/s41598-017-04312-5

24. The Chinese air quality online monitoring system. History data. (2015-2016). Available online at: https://www.aqistudy.cn/historydata/

25. Lee KK, Miller MR, Shah ASV. Air pollution and stroke. J Stroke. (2018) 20:2-11. doi: 10.5853/jos.2017.02894

26. Mills NL, Tornqvist H, Robinson SD, Gonzalez M, Darnley K, MacNee $\mathrm{W}$, et al. Diesel exhaust inhalation causes vascular dysfunction and impaired endogenous fibrinolysis. Circulation. (2005) 112:3930-6. doi: 10.1161/CIRCULATIONAHA.105.588962

27. Gong KW, Zhao W, Li N, Barajas B, Kleinman M, Sioutas C, et al. Air-pollutant chemicals and oxidized lipids exhibit genome-wide synergistic effects on endothelial cells. Genome Biol. (2007) 8:R149. doi: 10.1186/gb-2007-8-7-r149

28. Rao X, Zhong J, Brook RD, Rajagopalan S. Effect of particulate matter air pollution on cardiovascular oxidative stress pathways.
Antioxid Redox Signal. (2018) 28:797-818. doi: 10.1089/ars.201 7.7394

29. Routledge HC, Manney S, Harrison RM, Ayres JG, Townend JN. Effect of inhaled sulphur dioxide and carbon particles on heart rate variability and markers of inflammation and coagulation in human subjects. Heart. (2006) 92:220-7. doi: 10.1136/hrt.2004.051672

30. Thomson EM, Kumarathasan P, Calderon-Garciduenas L, Vincent R. Air pollution alters brain and pituitary endothelin-1 and inducible nitric oxide synthase gene expression. Environ Res. (2007) 105:224-33. doi: 10.1016/j.envres.2007.06.005

Conflict of Interest: The authors declare that the research was conducted in the absence of any commercial or financial relationships that could be construed as a potential conflict of interest.

Publisher's Note: All claims expressed in this article are solely those of the authors and do not necessarily represent those of their affiliated organizations, or those of the publisher, the editors and the reviewers. Any product that may be evaluated in this article, or claim that may be made by its manufacturer, is not guaranteed or endorsed by the publisher.

Copyright (C) 2022 Chen, Cheng, Li, Luo, Duan, Fan, Xu, Pu and Zhou. This is an open-access article distributed under the terms of the Creative Commons Attribution License (CC BY). The use, distribution or reproduction in other forums is permitted, provided the original author(s) and the copyright owner(s) are credited and that the original publication in this journal is cited, in accordance with accepted academic practice. No use, distribution or reproduction is permitted which does not comply with these terms. 